\title{
Social determinants of malaria in an endemic area of Indonesia
}

\author{
Hamzah Hasyim ${ }^{1,2^{*}} \mathbb{D}$, Pat Dale ${ }^{3}$, David A. Groneberg ${ }^{1}$, Ulrich Kuch ${ }^{1 \dagger}$ and Ruth Müller ${ }^{1,4 \dagger}$
}

\begin{abstract}
Background: Malaria is an increasing concern in Indonesia. Socio-demographic factors were found to strongly influence malaria prevalence. This research aimed to explore the associations between socio-demographic factors and malaria prevalence in Indonesia.

Methods: The study used a cross-sectional design and analysed relationships among the explanatory variables of malaria prevalence in five endemic provinces using multivariable logistic regression.

Results: The analysis of baseline socio-demographic data revealed the following independent risk variables related to malaria prevalence: gender, age, occupation, knowledge of the availability of healthcare services, measures taken to protect from mosquito bites, and housing condition of study participants. Multivariable analysis showed that participants who were unaware of the availability of health facilities were 4.2 times more likely to have malaria than those who were aware of the health facilities (adjusted odds ratio $=4.18 ; 95 \% \mathrm{Cl} 1.52-11.45 ; P=0.005$ ).

Conclusions: Factors that can be managed and would favour malaria elimination include a range of prevention behaviours at the individual level and using the networks at the community level of primary healthcare centres. This study suggests that improving the availability of a variety of health facilities in endemic areas, information about their services, and access to these is essential.
\end{abstract}

Keywords: Multivariable analysis, Malaria prevalence, Social health determinants, Social epidemiology, Community health services

\section{Background}

Malaria is a significant public health problem especially in developing countries including Indonesia [1]. Research has shown an enhanced interest in the social aspects of the epidemiology of malaria prevalence [2]. Socio-demographic, environmental, economic, cultural and behavioural factors determine the frequency, severity and outcome of malaria infection [3, 4]. Based on the Indonesian basic health research (Riskesdas) the prevalence of malaria in 2013 was $6.0 \%$. The distribution of the disease is focussed on eastern Indonesia $[5,6]$. Of 497

\footnotetext{
*Correspondence: hamzah.hasyim@stud.uni-frankfurt.de;

hamzah@fkm.unsri.ac.id

${ }^{\dagger}$ Ulrich Kuch and Ruth Müller act as equivalent co-senior authors

${ }^{1}$ Institute for Occupational Medicine, Social Medicine and Environmental Medicine, Faculty of Medicine, Goethe University, Frankfurt Am Main,

Germany

Full list of author information is available at the end of the article
}

districts/municipalities of Indonesia, $54 \%$ are endemic areas for malaria. The Ministry of Health $(\mathrm{MoH})$ strategy plan for malaria morbidity targeted an Annual Parasite Incidence (API) of $<1$ per 1000 population at risk by 2015 [7]. Nationally, malaria morbidity decreased from 4.1 per 1000 people in 2005 to 0.85 per 1000 by 2015 [7]. Reducing the anopheline vectors has been the subject of many meetings and public health initiatives for decades [8]. It has been proposed to eliminate malaria from Indonesia by 2030, with a variety of agendas particularly for endemic areas [9]. As the burden of malaria is very complicated, its elimination, implemented through an integrated approach, has become an integral part of national development [10]. This study attempts to identify socio-demographic factors that are related to malaria prevalence in Indonesia, such as the characteristics of participants, knowledge of the accessibility and utilization of health services, environmental health factors 


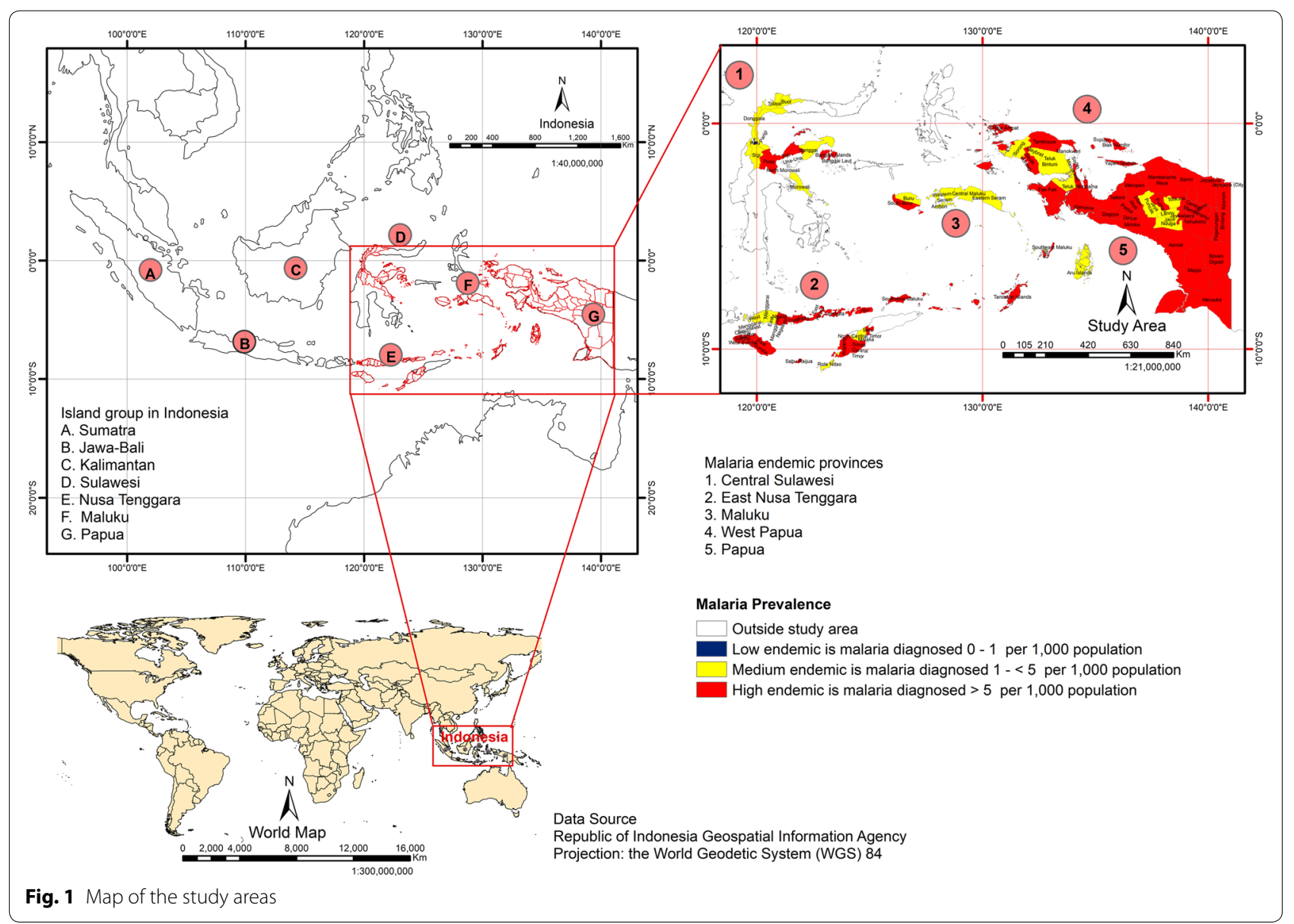

including personal measures to protect from mosquito bites, and the condition of housing structures.

\section{Methods}

\section{Study area}

The study area covered five out of 33 provinces of Indonesia (83 out of 497 districts and cities in 2013): Central Sulawesi, East Nusa Tenggara, Maluku, Papua, and West Papua Provinces (Fig. 1). These provinces were selected because they had been shown to be highly endemic for malaria both in the 2007 and 2013 basic health research of Indonesia $[5,6]$. A "highly malaria endemic" area was defined as having $>5$ cases of malaria diagnosed per 1000 population and year which is consistent with the API classification by the $\mathrm{MoH}$ of Indonesia. The software ArcGIS 10.3.1 was used for mapping, processing, analysis, and visualization of the data set, and WGS84 was used as the reference coordinate system.

\section{Research design}

The design of the Indonesian basic health research, which is called Riskesdas, is a descriptive cross-sectional survey to describe public health problems throughout Indonesia [6]. Figure 2 shows its framework for malaria research. The sample comprised 130,585 participants who represented the population in five highly malaria-endemic provinces.

\section{Research variables}

The dependent variable was malaria prevalence and is binary, that is, whether malaria was present or absent. The definition of disease used was diagnosis of the participants (D) with malaria by a physician or professional health worker (Additional file 1: Appendix S1). The data were obtained from a retrospective assessment by health surveyors using a standardised questionnaire. Participants who claimed to have never been diagnosed with malaria were asked whether they had suffered from the specific signs and clinical symptoms of the disease. The term "diagnosed/clinical symptoms" means that the prevalence of illness was based on the diagnosis by a physician or health worker in a health centre or based on the signs and symptoms experienced and reported by participants. The report referred to the disease information 


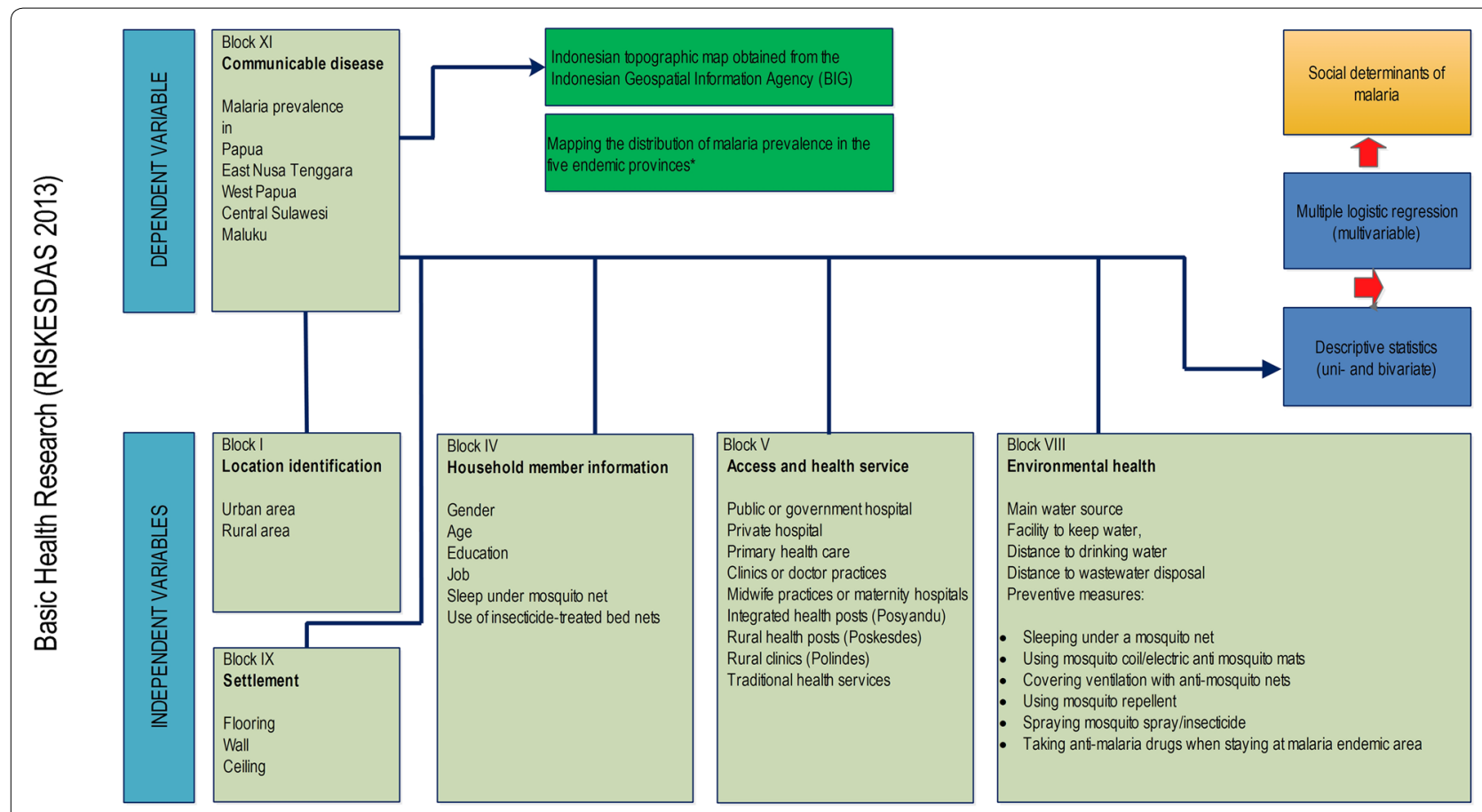

Fig. 2 Framework determinants of malaria among participants in the selected area

collected from interviews using questionnaires and clinically measured interviews $[5,6]$. The dependent variable, malaria prevalence, was summarized as a binary variable whose value was one if health experts assessed a participant as having had malaria within the past month $[5,6]$. In general, rapid diagnostic tests (RDTs) and microscopy were used to diagnose the disease, but the surveyor did not examine for malaria infection $[5,6]$.

The explanatory variables consisted of several sociodemographic factors that could affect malaria prevalence including the characteristics of participants, the availability of healthcare services, environmental sanitation including behaviour to prevent mosquito bites, and settlement (Fig. 2, Additional file 1: Appendix S1). These variables were grouped into blocks based on the questionnaire: block I-location identification or household information; block IV-household member information includes sex, age group (year), education and job (occupation), use of bed nets for sleeping and net insecticide; block V-knowledge of available healthcare facilities; block VIII-environmental health including prevention measures against malaria; and block IX-settlement (condition of housing structure). These were the criteria for environmental health in Riskesdas 2013 (joint monitoring programme World Health Organization-the United Nations Children's Fund criteria). Using logistic regression, the independent variables were standardized and modified by considering the survey design [11].
Variables that were transformed into categorical variables were: knowledge of available healthcare facilities, environmental sanitation, prevention measures, and condition of housing structure. All variables were coded as binary dummy variables coded 0 as referent category and coded 1 for a response category of an explanatory variable. Stata was used for data management and analysis [12, Additional file 1: Appendix S1].

\section{Descriptive analysis}

The descriptive analysis aimed to identify the characteristics of the independent variables in relation to the dependent variable, malaria prevalence. The variables are summarized in Table 1 and show the baseline sociodemographic characteristics of study participants. The magnitude of risk for having malaria was assessed from the calculated odds ratio (OR) and AOR (bi- and multivariable logistic regression test). If an OR was higher than one, the likelihood of contracting malaria was increased.

\section{Bivariate analysis}

The connections between each explanatory variable and the response variable were analysed with bivariate statistics. The Wald test from logistic regression used a $P$ cut-off point of 0.25 because statistical significance may not capture importance and the more traditional levels, such as $P$ of 0.05 , could fail to select variables known to be essential [13]. A cut-off value of 0.25 is supported by 
Table 1 Univariate and bivariate analysis of baseline socio-demographic characteristics of participants

\begin{tabular}{|c|c|c|c|c|}
\hline Research variables & $n=130,585$ & $95 \% \mathrm{Cl}(\mathrm{lb}-\mathrm{ub})^{\mathrm{a}}$ & OR; $95 \% \mathrm{Cl}(\mathrm{lb}-\mathrm{ub})^{\mathrm{b}}$ & P-value \\
\hline \multicolumn{5}{|l|}{ Malaria } \\
\hline No & 116,073 & $89.90(89.15-90.6)$ & & \\
\hline Yes & 14,512 & $10.10(9.40-10.85)$ & & \\
\hline \multicolumn{5}{|l|}{ Independent variables } \\
\hline \multicolumn{5}{|l|}{ Location } \\
\hline Urban & 37,389 & $25.60(23.07-28.31)$ & & \\
\hline Rural & 93,196 & $74.40(71.69-76.93)$ & $0.91(0.76-1.09)$ & 0.305 \\
\hline \multicolumn{5}{|l|}{ Socio-demographic characteristics } \\
\hline \multicolumn{5}{|l|}{ Gender } \\
\hline Male & 64,796 & $51.08(50.76-51.40)$ & & \\
\hline Female & 65,789 & $48.92(48.60-49.24)$ & $0.90(0.85-0.94)$ & 0.000 \\
\hline \multicolumn{5}{|l|}{ Age of participants in years } \\
\hline $0-4$ & 10,109 & $8.52(8.27-8.78)$ & & \\
\hline $5-14$ & 33,378 & $26.06(25.60-26.52)$ & $1.32(1.18-1.49)$ & 0.000 \\
\hline $15-24$ & 17,623 & $15.49(15.09-15.90)$ & $1.29(1.14-1.47)$ & 0.000 \\
\hline $25-34$ & 19,420 & $17.09(16.70-17.47)$ & $1.45(1.29-1.64)$ & 0.000 \\
\hline $35-44$ & 19,604 & $13.77(13.47-14.09)$ & $1.58(1.39-1.80)$ & 0.000 \\
\hline $45-54$ & 14,170 & $8.90(8.65-9.17)$ & $1.42(1.24-1.62)$ & 0.000 \\
\hline $55-64$ & 8312 & $4.84(4.64-5.05)$ & $1.27(1.09-1.50)$ & 0.003 \\
\hline $65-74$ & 3927 & $2.38(2.25-2.52)$ & $1.14(0.96-1.36)$ & 0.147 \\
\hline$>75$ & 4042 & $2.94(2.81-3.08)$ & $1.33(1.12-1.58)$ & 0.001 \\
\hline \multicolumn{5}{|l|}{ Education } \\
\hline Participants considered as higher educated & 5935 & $4.193(3.853-4.562)$ & & \\
\hline Participants who had not completed high school education & 94,644 & $72.08(71.33-72.83)$ & $0.99(0.83-1.18)$ & 0.878 \\
\hline Participants under 10 years or in preschool & 30,006 & $23.72(22.93-24.54)$ & $0.84(0.69-1.03)$ & 0.092 \\
\hline \multicolumn{5}{|l|}{ Job (occupation) } \\
\hline Participants who were not working & 77,533 & $60.12(59.42-60.82)$ & & \\
\hline Participants who were working & 53,052 & $39.88(39.18-40.58)$ & $1.20(1.12-1.27)$ & 0.000 \\
\hline \multicolumn{5}{|l|}{ Use of mosquito nets } \\
\hline Participants who used mosquito nets at night & 61,779 & $46.19(44.12-48.27)$ & & \\
\hline Participants who did not use mosquito nets at night & 68,806 & $53.81(51.73-55.88)$ & $1.09(0.97-1.23)$ & 0.153 \\
\hline \multicolumn{5}{|l|}{ Use of $\mathrm{i}$ insecticide-treated mosquito nets } \\
\hline Yes & 32,150 & $23.26(21.73-24.85)$ & & \\
\hline No & 27,510 & $21.49(20.03-23.02)$ & $0.90(0.78-1.04)$ & 0.154 \\
\hline Participants who did not answer and others & 70,925 & $55.26(53.18-57.31)$ & $1.05(0.91-1.20)$ & 0.517 \\
\hline \multicolumn{5}{|c|}{ Knowledge of households about the healthcare facilities closest to their residence } \\
\hline \multicolumn{5}{|c|}{ Public hospital } \\
\hline Known & 64,817 & $48.97(46.47-51.46)$ & & \\
\hline Not known & 65,768 & $51.03(48.54-53.53)$ & $0.80(0.69-0.92)$ & 0.002 \\
\hline \multicolumn{5}{|l|}{ Private hospital } \\
\hline Known & 27,836 & $22.44(20.32-24.70)$ & & \\
\hline Not known & 102,749 & $77.56(75.30-79.68)$ & $0.65(0.55-0.76)$ & 0.000 \\
\hline \multicolumn{5}{|l|}{ Secondary or primary healthcare unit } \\
\hline Known & 116,609 & $88.92(87.65-90.08)$ & & \\
\hline Not known & 13,976 & $11.08(9.92-12.35)$ & $0.84(0.70-1.00)$ & 0.051 \\
\hline \multicolumn{5}{|l|}{ Clinics or practices of doctors } \\
\hline Known & 32,954 & $25.7(23.73-27.77)$ & & \\
\hline Not known & 97,631 & $74.3(72.23-76.27)$ & $0.84(0.73-0.97)$ & 0.019 \\
\hline
\end{tabular}


Table 1 (continued)

\begin{tabular}{|c|c|c|c|c|}
\hline Research variables & $n=130,585$ & $95 \% \mathrm{Cl}(\mathrm{lb}-\mathrm{ub})^{\mathrm{a}}$ & OR; $95 \% \mathrm{Cl}(\mathrm{lb}-\mathrm{ub})^{\mathrm{b}}$ & P-value \\
\hline \multicolumn{5}{|c|}{ Midwife practices or maternity hospitals } \\
\hline Known & 18,387 & $16.59(14.82-18.52)$ & & \\
\hline Not known & 112,198 & $83.41(81.48-85.18)$ & $1.46(1.24-1.72)$ & 0.000 \\
\hline \multicolumn{5}{|c|}{ Integrated health posts (Posyandu) } \\
\hline Known & 56,129 & $43.23(41.01-45.47)$ & & \\
\hline Not known & 74,456 & $56.77(54.53-58.99)$ & $1.19(1.06-1.35)$ & 0.004 \\
\hline \multicolumn{5}{|c|}{ Village health posts (Poskesdes) } \\
\hline Known & 9932 & $7.85(6.63-9.26)$ & & \\
\hline Not known & 120,653 & $92.15(90.74-93.37)$ & $1.90(1.46-2.47)$ & 0.000 \\
\hline \multicolumn{5}{|c|}{ Village maternity clinic (Polindes) } \\
\hline Known & 17,312 & $14.61(12.95-16.43)$ & & \\
\hline Not known & 113,273 & $85.39(83.57-87.05)$ & $1.16(0.97-1.40)$ & 0.109 \\
\hline \multicolumn{5}{|c|}{ Environmental sanitation } \\
\hline \multicolumn{5}{|c|}{ Main water source } \\
\hline Improved & 94,267 & $72.88(70.77-74.88)$ & & \\
\hline Unimproved & 36,318 & $27.12(25.12-29.23)$ & $1.10(0.95-1.27)$ & 0.226 \\
\hline \multicolumn{5}{|l|}{ Water storage facility } \\
\hline Improved & 127,808 & $97.56(96.99-98.03)$ & & \\
\hline Unimproved & 2777 & $2.44(1.97-3.01)$ & $1.32(0.97-1.80)$ & 0.076 \\
\hline \multicolumn{5}{|c|}{ Distance from drinking water (time needed to obtain water for drinking) } \\
\hline Improved & 108,053 & $82.1(80.44-83.64)$ & & \\
\hline Unimproved & 22,532 & $17.9(16.36-19.56)$ & $0.90(0.77-1.06)$ & 0.218 \\
\hline \multicolumn{5}{|l|}{ Wastewater disposal } \\
\hline Improved & 24,099 & $18.76(17.35-20.25)$ & & \\
\hline Unimproved & 106,486 & $81.24(79.75-82.65)$ & $1.12(0.98-1.27)$ & 0.089 \\
\hline \multicolumn{5}{|c|}{ Slept using a mosquito net } \\
\hline Yes & 63,333 & $47.44(45.35-49.54)$ & & \\
\hline No & 67,252 & $52.56(50.46-54.65)$ & $1.15(1.03-1.29)$ & 0.018 \\
\hline \multicolumn{5}{|c|}{ Using mosquito coil/electric anti-mosquito mats } \\
\hline Yes & 39,875 & $31.42(29.60-33.29)$ & & \\
\hline No & 90,710 & $68.58(66.71-70.40)$ & $1.27(1.13-1.42)$ & 0.000 \\
\hline \multicolumn{5}{|c|}{ Covering ventilation holes with anti-mosquito nets } \\
\hline Yes & 8582 & $6.25(5.43-7.18)$ & & \\
\hline No & 122,003 & $93.75(92.82-94.57)$ & $0.52(0.43-0.62)$ & 0.000 \\
\hline \multicolumn{5}{|c|}{ Using mosquito repellent } \\
\hline Yes & 6562 & $4.76(4.18-5.43)$ & & \\
\hline No & 124,023 & $95.24(94.57-95.82)$ & $1.06(0.85-1.31)$ & 0.616 \\
\hline \multicolumn{5}{|c|}{ Spraying mosquito spray/insecticide } \\
\hline Yes & 12,004 & $9.11(8.10-10.22)$ & & \\
\hline No & 118,581 & $90.90(89.78-91.90)$ & $0.66(0.55-0.79)$ & 0.000 \\
\hline \multicolumn{5}{|c|}{ Taking anti-malaria drugs when staying in a malaria endemic area } \\
\hline Yes & 1265 & $0.92(0.73-1.16)$ & & \\
\hline No & 129,320 & $99.08(98.84-99.27)$ & $0.48(0.33-0.69)$ & 0.000 \\
\hline \multicolumn{5}{|c|}{ Draining the bath water reservoir once a week } \\
\hline Yes & 55,702 & $41.89(39.97-43.83)$ & & \\
\hline No & 74,883 & $58.11(56.17-60.03)$ & $0.98(0.87-1.10)$ & 0.698 \\
\hline \multicolumn{5}{|c|}{ Settlement or housing condition } \\
\hline \multicolumn{5}{|l|}{ Floors } \\
\hline Improved & 51,788 & $39.82(37.95-41.73)$ & & \\
\hline
\end{tabular}


Table 1 (continued)

\begin{tabular}{|c|c|c|c|c|}
\hline Research variables & $n=130,585$ & $95 \% \mathrm{Cl}(\mathrm{lb}-\mathrm{ub})^{\mathrm{a}}$ & OR; $95 \% \mathrm{Cl}(\mathrm{lb}-\mathrm{ub})^{\mathrm{b}}$ & P-value \\
\hline Unimproved & 78,797 & $60.18(58.27-62.05)$ & $1.23(1.08-1.39)$ & 0.001 \\
\hline \multicolumn{5}{|l|}{ Walls } \\
\hline Improved & 112,582 & $85.23(83.59-86.72)$ & & \\
\hline Unimproved & 18,003 & $14.77(13.28-16.41)$ & $1.32(1.122-1.55)$ & 0.001 \\
\hline \multicolumn{5}{|l|}{ Ceiling } \\
\hline Improved & 2192 & $1.75(1.45-2.10)$ & & \\
\hline Unimproved & 128,393 & $98.26(97.90-98.55)$ & $1.04(0.72-1.50)$ & 0.835 \\
\hline
\end{tabular}

literature [14]. Decisions to keep a variable in the "best" model were based on clinical or statistical significance, or on the significance level of a confounder between 0.1 and 0.15 as it might, in combination with other variables, make an important contribution [13]. In the present study, variables could potentially be entered into the multivariable model if the results of the bivariate test had a value of $P<0.25$.

\section{Multivariable analysis}

The multivariable analysis aimed to find the parsimonious logistic regression model. A backward technique was used with stepwise removal of non-significant variables $(P>0.05)$. The regression coefficient was repeatedly re-estimated until no further independent variables were insignificant. However, if $P>0.05$, the variable was inserted into the multivariable model but only if considered substantially necessary. The variables that had significant results in the descriptive analysis of each variable were selected as candidates for the model for multivariable analysis.

\section{Results}

Figure 1 reveals a low prevalence of diagnosed malaria disease at Palu (0.85\%) and Donggala (1.56\%) districts in Central Sulawesi, and a high malaria prevalence at Intan Jaya (45.96\%) and Kepulauan Yapen (38.95\%) districts in Papua.

\section{Descriptive analysis}

The effect of social determinants on malaria prevalence in five malaria-endemic provinces of Indonesia is summarised in Table 1 and more detailed in Additional file 2: Appendix S2. A large percentage of participants (72.08\%) had not completed high school education, and only $4.19 \%$ were considered higher educated. Overall the percentage of males $(51.08 \%)$ was slightly higher than that of females (48.92\%). An OR $>1$ shows that the probability of the disease is greater for the response category than the referent category of an explanatory variable. The percentage of respondents who reported "do not know the availability of midwife practices, and village health post" was $83.41 \%$ and $92.15 \%$, respectively. In the bivariate analysis, participants who were working were 1.2 times more likely to have malaria than those who were not $(\mathrm{OR}=1.20$; 95\% CI $1.12-$ $1.27 ; P<0.001)$. The environmental sanitation variable was not statistically significantly associated with malaria prevalence $(\mathrm{OR}=1.13$; 95\% CI 0.99-1.31; $P=0.081)$. Prevention measures against malaria were important: participants who did not take preventive measures were 1.2 times more likely to contract malaria than those who did $(\mathrm{OR}=1.18$; 95\% CI 1.01-1.38; $P=0.036$ ). The risk of having malaria was significantly higher for participants who did not know about the availability of healthcare services $(\mathrm{OR}=4.22$; $95 \%$ CI 1.53-11.59; $P=0.005)$. Further, housing conditions were also important: participants who lived in houses made of unimproved materials were 1.3 times more likely to have malaria than those in houses made of improved building materials $(\mathrm{OR}=1.30 ; 95 \% \mathrm{CI} 1.09-1.54 ; P=0.003)$ as shown in Table 2.

\section{Logistic multivariable regression}

The OR and AOR of factors affecting malaria prevalence are shown in Table 2 and more detailed in Additional file 2: Appendix S2. The participants who were unaware of the availability of or did not utilize health facilities were more likely to have malaria than those who did (AOR $=4.18 ; 95 \%$ CI $1.52-11.45 ; P=0.005$; adjusted by other covariates). The logistic multivariable regression provides an additional dimension to the research results (Table 2). The final model includes the following significant explanatory variables for malaria prevalence: characteristics of participants (gender, age, and job in block IV), knowledge of the availability of health services (in block V), and settlement (condition of housing structure in block IX). 
Table 2 Factors associated with malaria prevalence in the endemic area

\begin{tabular}{|c|c|c|c|c|}
\hline \multirow[t]{2}{*}{ Research variables } & \multicolumn{2}{|c|}{ Simple logistic regression analysis } & \multicolumn{2}{|c|}{ Multiple logistic regression analysis } \\
\hline & OR $(95 \% \mathrm{Cl})^{\mathrm{a}}$ & P-value & AOR $(95 \% \mathrm{CI})^{b}$ & P-value \\
\hline \multicolumn{5}{|l|}{ Gender } \\
\hline \multicolumn{5}{|l|}{ Males (Ref.) } \\
\hline Females & $0.90(0.85-0.94)$ & 0.000 & $0.91(0.87-0.96)$ & 0.000 \\
\hline \multicolumn{5}{|l|}{ Age of participants in years } \\
\hline \multicolumn{5}{|l|}{ More than 5 years of age (Ref.) } \\
\hline Children under 5 years of age & $0.72(0.65-0.81)$ & 0.000 & $0.74(0.67-0.83)$ & 0.000 \\
\hline \multicolumn{5}{|l|}{ Job (occupation) } \\
\hline \multicolumn{5}{|l|}{ Participants who were not working (Ref.) } \\
\hline Participants who were working & $1.20(1.12-1.27)$ & 0.000 & $1.13(1.06-1.20)$ & 0.000 \\
\hline \multicolumn{5}{|l|}{ Use of mosquito nets } \\
\hline \multicolumn{5}{|l|}{ Participants who used mosquito nets (Ref.) } \\
\hline Participants who did not use mosquito nets & $1.09(0.97-1.23)$ & 0.153 & - & - \\
\hline \multicolumn{5}{|l|}{ Knowledge about healthcare services } \\
\hline \multicolumn{5}{|l|}{ Healthcare facilities closest to the residence } \\
\hline \multicolumn{5}{|l|}{ Known (Ref.) } \\
\hline Not known & $4.22(1.53-11.59)$ & 0.005 & $4.18(1.52-11.45)$ & 0.005 \\
\hline \multicolumn{5}{|l|}{ Environmental health } \\
\hline \multicolumn{5}{|l|}{ Improved (Ref.) } \\
\hline Unimproved & $1.13(0.99-1.31)$ & 0.081 & - & - \\
\hline \multicolumn{5}{|l|}{ Preventive measures } \\
\hline \multicolumn{5}{|l|}{ Using preventive measures (Ref.) } \\
\hline Not using preventive measures & $1.18(1.01-1.38)$ & 0.036 & - & - \\
\hline \multirow{2}{*}{\multicolumn{5}{|c|}{$\begin{array}{l}\text { Settlement or housing condition } \\
\text { Improved (Ref.) }\end{array}$}} \\
\hline & & & & \\
\hline Unimproved & $1.30(1.09-1.54)$ & 0.003 & $1.30(1.09-1.54)$ & 0.003 \\
\hline
\end{tabular}

\section{Discussion}

\section{Principal findings}

Many risk factors increase the likelihood of contracting malaria, particularly the accessibility and utilization of primary healthcare facilities. This study reveals a 4.2-fold increase in the odds of malaria prevalence for participants who do not know about the availability of healthcare facilities compared to those who do know, adjusted by other covariates. The kind of healthcare facilities in this study included government hospitals, private hospitals, primary healthcare (puskesmas), clinics, midwife practices, integrated health posts (posyandu), village health posts (poskesdes), and village maternity clinics (polindes). Health services at the primary level in the community as well as their networks are essential for malaria elimination. Healthcare services, particularly for pregnant women, can be delivered during antenatal care (ANC) as pregnant women, infants, and toddlers are especially vulnerable groups for the disease. Malaria is a significant global health issue, especially among pregnant women [15]. Midwives also play a crucial role in health reporting [16]. Although there are physicians and nurses in public and private hospitals, midwives are also needed at the primary level of healthcare and at the community level. Thus, they also need to be equipped with expertise and skills to effectively provide information and promote the prevention of malaria. Particularly at the community level such health promotion and malaria prevention programmes are essential [17]. The findings of this study are consistent with those of one in Uganda where midwives provide malaria-related health promotion and education to pregnant women during every prenatal clinic visit, including direct supervision on how to consume drugs [18]. In sub-Saharan Africa, it has long been recognized that pregnant women are an especially vulnerable group for malaria infection, and that there is a need for active management of the disease in pregnancy as a fundamental part of antenatal care in endemic areas [19]. 
In Malawi, pregnant women are significant reservoirs of gametocyte transmission which is present in 5\% at their first antenatal care visit, and this should not be overlooked in elimination efforts [20].

\section{Explanatory variables}

In the present study, the estimated odds of malaria in females was $10 \%$ lower than in males. Similarly, in Lundu district, Sarawak, Malaysia, malaria infection was associated in male than a female with seven-fold risk to be malaria-infected [21]. This is consistent with a previous study showing that females performed a protective function in malaria control [22]. In contrast, in Bungoma county, western Kenya, the risk of clinical malaria was related to being female. As well, Plasmodium falciparum infection was connected with being male, poorer, and malnourished [23]. Malaria prevalence differs among age groups. In this study, the estimated odds of malaria for the age group from 35 to 44 years were higher than for others. In a similar study in sub-Saharan Africa, a positive microscopic result was significantly associated with being in the age group of 35-44 years compared to 45 years or older [24]. Also, in South Africa malaria is a significant public health problem among adults and more pronounced in the economically active adult male population [25]. Another study in rural Hausa communities in Nigeria showed that malaria was significantly associated with the participant's knowledge, age, and gender [26]. In the present study, the risk of having malaria was 1.2 to 1.13 times higher for those who were working (simple logistic and multiple logistic analysis, respectively) compared to those who were not. Conversely, in a study in Blantyre, Malawi, employment status did not differ between the groups [27].

Several other factors are related to malaria prevalence. These include the lack of prevention measures against malaria, such as bed nets, insecticide treatment and knowledge deficits. In spite of a widespread use of mosquito nets at night and insecticide-treated mosquito nets (ITNs), this is not always significantly associated with reduced malaria prevalence. Nevertheless, the present study indicates that participants in endemic provinces of Indonesia who did not use mosquito nets at night were more likely to have malaria than those who did. Similarly, not using ITNs predicted an increased occurrence of clinical malaria in a study in urban Kano, northwestern Nigeria [28], and an Indian study found that a persistent use of nets resulted in a substantial reduction in malaria cases [29]. Illustrating the variability of the relationship between bed-net use and malaria incidence, a study in southern Ethiopia, where the use of bed-nets was frequent, showed that the prevalence of malaria was also high [30]. Obstacles to the use of ITNs include lack of promotion information and lack of knowledge [31]. A survey in Orissa, India, indicated that appropriate communication strategies should be built up and imparted alongside ITN distribution to promote ITN adoption [31]. A similar finding was reported for south-eastern Nigeria where, despite the community having good knowledge about the use of mosquito nets, few knew about the existence of ITNs [32]. Another investigation in Ghana revealed that participants did not have sufficient knowledge about the behaviour of mosquitoes, which weakened their knowledge of the relationship between malaria control and the use of ITNs [33].

Lack of both information and vector control measures to protect people from malaria have been reported as being related to higher malaria risk [34]. Unquestionably, the dissemination of information and health education for preventive measures against malaria are essential. In a South African study, most participants were confident that indoor residual spraying killed mosquitoes and prevented infection. Their sources of malaria information were from the local health facility, radio, and community meetings [35]. The latter study considered that providing health education on malaria and knowledge about risk factors might change health-related behaviour, and thereupon the spreading of knowledge could decrease malaria infection [30]. The present research in the context of Indonesia concludes that preventive measures against malaria in the environment are important.

Knowledge about the availability of health facilities is also important. This study revealed a 4.2-fold increase of malaria prevalence in participants who did not know about the availability of health facilities compared to participants who did. Increasing distance from the place of residence to the nearest health centre was related to delays in seeking treatment for severe malaria at Jinja Hospital, Uganda [30, 36]. In Cambodia, knowledge about malaria symptoms differed significantly between a village with a health centre and an area that had only village malaria workers. Thus, governments need to enhance community knowledge about malaria symptoms and case management in rural areas [37].

Similarly, in sub-Saharan Africa malaria transmission was determined by knowledge of and access to malaria prevention tools as well as healthcare services [38]. In Mali, knowledge and perceptions related to health condition have an important influence on care-seeking behaviour in the formal health sector [39]. The government of Ghana improved access to healthcare, particularly in a primary healthcare programme, and that was an important contribution towards malaria elimination [40]. In the Asia-Pacific region, the use of traditional medicine and/or traditional healers to treat malaria was related to lack of access to health services (due to geographical or 
economic barriers), belief in traditional medicine, and a perception that symptoms of malaria were less severe a disease [41]. In central Cameroon, rural populations tended to visit traditional practitioners more than urban healthcare providers for geographical and financial reasons [42]. Optimizing the role of the "alert village" where the people of the village can easily access health services through village health posts or other health facilities in the area will reduce malaria risk. The alert village is a strategic effort that was created to accelerate the achievement of the millennium development goals to combat malaria [43]. As noted above, the present study concludes that participants who were unaware of available health facilities were more likely to have malaria than those who did know about these.

Even though environmental sanitation was not significantly associated with malaria prevalence in this study, participants who lived in environments with unimproved sanitation more frequently had malaria than those living in environments with improved sanitation. In a Nigerian study, the majority of respondents believed that bushes around the house were significant facilitators of malaria. Some of them stated that the presence of stagnant water was associated with malaria while others mentioned unclean drainage systems [29]. Keeping the outside environment clean can reduce the risk of malaria as shown in a study in rural Nigeria where reductions of malaria prevalence were significantly associated with periodic cleaning of the external environment [44].

With regards to housing condition, the estimated odds ratio of malaria prevalence for participants who lived in houses made of unimproved materials showed that they were 1.3 times more likely to have malaria than those living in houses made of improved building materials. This is consistent with the results of a study in Nigeria where the odds of malaria infection were significantly higher among participants who lived in unimproved houses [45]. A recent review noted that low-quality housing was consistently associated with malaria prevalence, and the authors recommended that this should be further explored along with housing improvements, especially those that reduce mosquito access [46]. A study in the Ananindeua municipality, State of Pará (Brazil), showed an association between poverty and poor living conditions and highlighted that these need to be considered in malaria prevention and control strategies [47]. Another study, conducted in Equatorial Guinea, showed connections between improved building materials over time, housing quality (closed eaves and door/window screens), and reduced malaria incidence [48]. A study in Krogwe, Tanzania, showed that children living in high-quality housing had only a third of the malaria infections compared to those living in poor quality housing [49]. In addition, location is important with households that are very close to the border of forests and swamps being at high risk for malaria $[4,50]$. To sum up, unimproved conditions of housing structure were associated with higher malaria prevalence.

\section{Limitations of research}

Malaria disease status was retrospectively assessed by a standard Riskesdas questionnaire and not directly based on diagnoses made by healthcare professionals. Thus, the prevalence of malaria could only be estimated from respondents who reported that they had been diagnosed with malaria by professional health workers. There may be other factors which affect malaria prevalence but were not monitored in the Riskesdas survey; these could be the subject of further research. Nevertheless, the present study has the strength of being based on a large sample size, and its analyses were novel and robust and identified relationships that could be useful in the future design of malaria control strategies, at least in the five highly endemic provinces of Indonesia.

\section{Conclusions}

This study estimated the socio-demographic factors affecting malaria prevalence in the five highly endemic provinces of Indonesia. These factors included the characteristics of participants, lack of knowledge about the availability of healthcare services, and unimproved housing. Recommendations include increasing community health education regarding the utilization of healthcare facilities, improving community healthcare knowledge, and practices relating to malaria prevention, such as improving the condition of housing structures. These should be considered in upcoming malaria management control strategies.

\section{Additional files}

Additional file 1: Appendix S1. Detailed explanation of the scope of variables and analytical method.

Additional file 2: Appendix S2. Detailed description of descriptive analysis.

\section{Abbreviations}

ANC: antenatal care; AOR: adjusted odds ratio; API: annual parasite incidence (number of slides positive for parasite $\times 1000 /$ total population); ArcGIS: aeronautical reconnaissance coverage geographic information system; Balitbangkes: Badan Penelitian dan Pengembangan Kesehatan (National Institute for Health Research and Development); Cl: confidence interval; HDI: Health Development Index; ITNs: insecticide-treated mosquito nets; $\mathrm{MoH}$ : Ministry of Health; OR: odds ratio/unadjusted odds ratio; Polindes: Pos bersalin desa (village maternity clinic); Poskesdes: Pos kesehatan desa (village health post); Posyandu: Pos pelayanan terpadu (integrated health post); Puskesmas: Pusat 
kesehatan masyarakat (primary health care centre); Pv: P-values; RDTs: rapid diagnostic tests; Riskesdas: Riset kesehatan dasar (Basic Health Research).

\section{Authors' contributions}

$\mathrm{HH}$ designed and performed the collection and analysis of the data and managed the study. PD, RM, DAG and UK contributed to the interpretation and visualization of the results. HH, PD, RM, DAG and UK wrote the paper. All authors read and approved the final manuscript.

\section{Author details}

${ }^{1}$ Institute for Occupational Medicine, Social Medicine and Environmental Medicine, Faculty of Medicine, Goethe University, Frankfurt Am Main, Germany. ${ }^{2}$ Faculty of Public Health, Sriwijaya University, Indralaya, South Sumatra, Indonesia. ${ }^{3}$ Environmental Futures Research Institute (EFRI), School of Environment \& Science, Griffith University, Nathan, QLD, Australia. ${ }^{4}$ Unit of Entomology, Institute of Tropical Medicine, 2000 Antwerp, Belgium.

\section{Acknowledgements}

The authors are grateful to the Ministry of Research, Technology and Higher Education of the Republic of Indonesia for supporting the first author $(\mathrm{HH})$ with a PhD scholarship in the context of the cooperation between Sriwijaya University and Goethe University. The authors thank the Balitbangkes who kindly permitted us to do further analyses of the Riskesdas 2013 data, and the Head of the Geospatial Information Agency of Indonesia for access to the digitized map.

\section{Competing interests}

The authors declare that they have no competing interests.

\section{Availability of data and materials}

The basic dataset of Riskesdas has been set up at the Balitbangkes of $\mathrm{MoH}$, and the secondary data is available upon request from the corresponding author $(H H)$.

\section{Consent for publication}

Not applicable.

\section{Ethics approval and consent to participate}

The ethical clearance for the collection and use of the primary data as the data source for this study was given to Riskesdas 2013 with the number LB.02.01/5.2/KE.006/2013. Ethical clearance was obtained from the National Ethical Committee of the Indonesian Ministry of Health (Balitbangkes) in Jakarta (official name: Komisi Nasional Etik Penelitian Kesehatan).

\section{Funding}

The Ministry of Research Technology and Higher Education of the Republic of Indonesia (number 124.63/E4.4/2014) funded the study of HH. The work of RM, UK and DAG was supported by the Federal Ministry of Education and Research of Germany under the project AECO (number 01Kl1717).

\section{Publisher's Note}

Springer Nature remains neutral with regard to jurisdictional claims in published maps and institutional affiliations.

Received: 16 November 2018 Accepted: 1 April 2019

Published online: 12 April 2019

\section{References}

1. Aimone AM, Perumal N, Cole DC. A systematic review of the application and utility of geographical information systems for exploring disease-disease relationships in paediatric global health research: the case of anaemia and malaria. Int J Health Geogr. 2013;12:1-13.

2. Bannister-Tyrrell M, Verdonck K, Hausmann-Muela S, Gryseels C, Muela Ribera J, Peeters Grietens K. Defining micro-epidemiology for malaria elimination: systematic review and meta-analysis. Malar J. 2017;16:164.

3. Manh BH, Clements AC, Thieu NQ, Hung NM, Hung LX, Hay SI, et al. Social and environmental determinants of malaria in space and time in Viet Nam. Int J Parasitol. 2011;41:109-16.
4. Hasyim H, Nursafingi A, Haque U, Montag D, Groneberg DA, Dhimal M, et al. Spatial modelling of malaria cases associated with environmental factors in South Sumatra, Indonesia. Malar J. 2018;17:87.

5. National Institute of Health Research and Development. Indonesia Basic Health Research (RISKESDAS) 2007. Jakarta: Ministry of Health (Indonesia); 2008.

6. National Institute of Health Research and Development (NIHRD). Indonesia Basic Health Research (RISKESDAS) 2013. Jakarta: Ministry of Health (Indonesia); 2014

7. Kementerian Kesehatan Republic of Indonesia. Profil kesehatan Indonesia tahun 2015. Jakarta: Kementerian Kesehatan Rl; 2016.

8. Elyazar I, Hay SI, Baird JK. Malaria distribution, prevalence, drug resistance and control in Indonesia. Adv Parasitol. 2011;74:41.

9. Murhandarwati EEH, Fuad A, Wijayanti MA, Bia MB, Widartono BS, Lobo $N F$, et al. Change of strategy is required for malaria elimination: a case study in Purworejo District, Central Java Province, Indonesia. Malar J. 2015;14:318.

10. Ministry of Health Republic of Indonesia. Decree Number 293/Menkes/ SK/IV/2009 concerning malaria elimination in Indonesia (Ministry of Health Republic of Indonesia ed. 2009.

11. Roberts G, Rao N, Kumar S. Logistic regression analysis of sample survey data. Biometrika. 1987;74:1-12.

12. Stata. Stata Survey Data Reference Manual Release 13. A Stata Press Publication, StataCorp LP, College Station, Texas; 2011.

13. Bursac Z, Gauss CH, Williams DK, Hosmer DW. Purposeful selection of variables in logistic regression. Source Code Biol Med. 2008;3:17.

14. Bendel RB, Afifi AA. Comparison of stopping rules in forward "stepwise" regression. J Am Stat Assoc. 1977;72:46-53.

15. Corrêa G, Das M, Kovelamudi R, Jaladi N, Pignon C, Vysyaraju K, et al. High burden of malaria and anemia among tribal pregnant women in a chronic conflict corridor in India. Confl Health. 2017;11:10.

16. Ngana FR, Myers BA, Belton S. Health reporting system in two subdistricts in Eastern Indonesia: highlighting the role of village midwives. Midwifery. 2012;28:809-15.

17. Mahendradhata Y, Trisnantoro L, Listyadewi S, Soewondo P, Marthias T, Harimurti P, et al. The Republic of Indonesia health system review. In: Health Systems in Transition India; World Health Organization, 2017.

18. Bbosa RS, Ehlers VJ. Midwives' provision of antimalaria services to pregnant women in Uganda. Midwifery. 2017;47:36-42.

19. Scott S, Mens PF, Tinto H, Nahum A, Ruizendaal E, Pagnoni F, et al. Community-based scheduled screening and treatment of malaria in pregnancy for improved maternal and infant health in The Gambia, Burkina Faso and Benin: study protocol for a randomized controlled trial. Trials. 2014;15:340.

20. Boudová S, Cohee LM, Kalilani-Phiri L, Thesing PC, Kamiza S, Muehlenbachs $A$, et al. Pregnant women are a reservoir of malaria transmission in Blantyre, Malawi. Malar J. 2014;13:506.

21. Jusoh N, Shah SA. Influence of risk perception, preventive behavior, movement and environment on malaria infection in Lundu district, Sarawak, Malaysia. Med J Indonesia. 2007;16:267-76.

22. Hasyim H, Dhimal M, Bauer J, Montag D, Groneberg DA, Kuch U, et al. Does livestock protect from malaria or facilitate malaria prevalence? A cross-sectional study in endemic rural areas of Indonesia. Malar J. 2018;17:302.

23. Kepha S, Nikolay B, Nuwaha F, Mwandawiro CS, Nankabirwa J, Ndibazza J, et al. Plasmodium falciparum parasitaemia and clinical malaria among school children living in a high transmission setting in western Kenya. Malar J. 2016;15:157.

24. Tadesse F, Fogarty AW, Deressa W. Prevalence and associated risk factors of malaria among adults in East Shewa Zone of Oromia Regional State, Ethiopia: a cross-sectional study. BMC Public Health. 2017;18:25.

25. Adeola AM, Botai O, Olwoch JM, Rautenbach CW, Adisa O, Taiwo O, et al. Environmental factors and population at risk of malaria in Nkomazi municipality, South Africa. Trop Med Int Health. 2016;21:675-86.

26. Dawaki S, Al-Mekhlafi HM, Ithoi I, Ibrahim J, Atroosh WM, Abdulsalam AM, et al. Is Nigeria winning the battle against malaria? Prevalence, risk factors and KAP assessment among Hausa communities in Kano State. Malar J. 2016;15:351.

27. Abrams ET, Kwiek JJ, Mwapasa V, Kamwendo DD, Tadesse E, Lema VM, et al. Malaria during pregnancy and foetal haematological status in Blantyre, Malawi. Malar J. 2005;4:39. 
28. Iliyasu Z, Babashani M, Abubakar IS, Salahudeen AA, Aliyu MH. Clinical burden and correlates of HIV and malaria co-infection, in northwest Nigeria. Acta Trop. 2013;128:630-5.

29. Ansari M, Razdan R. Bio-efficacy and operational feasibility of alphacypermethrin (Fendona) impregnated mosquito nets to control rural malaria in northern India. J Vector Borne Dis. 2003;40:33-42.

30. Debo GW, Kassa DH. Prevalence of malaria and associated factors in Benna Tsemay district of pastoralist community, Southern Ethiopia. Trop Dis Travel Med Vaccines. 2016;2:16.

31. Vijayakumar KN, Gunasekaran K, Sahu SS, Jambulingam P. Knowledge, attitude and practice on malaria: a study in a tribal belt of Orissa state, India with reference to use of long lasting treated mosquito nets. Acta Trop. 2009;112:137-42.

32. Onwujekwe OE, Akpala CO, Ghasi S, Shu EN, Okonkwo PO. How do rural households perceive and prioritise malaria and mosquito nets? A study in five communities of Nigeria. Public Health. 2000;114:407-10.

33. Kudom AA, Mensah BA. The potential role of the educational system in addressing the effect of inadequate knowledge of mosquitoes on use of insecticide-treated nets in Ghana. Malar J. 2010;9:256.

34. Forero DA, Chaparro PE, Vallejo AF, Benavides Y, Gutiérrez JB, Arévalo-Herrera $\mathrm{M}$, et al. Knowledge, attitudes and practices of malaria in Colombia. Malar J. 2014;13:165.

35. Manana PN, Kuonza L, Musekiwa A, Mpangane HD, Koekemoer LL. Knowledge, attitudes and practices on malaria transmission in Mamfene, KwaZulu-Natal Province, South Africa 2015. BMC Public Health. 2018;18:41.

36. Mpimbaza A, Ndeezi G, Katahoire A, Rosenthal PJ, Karamagi C. Demographic, socioeconomic, and geographic factors leading to severe malaria and delayed care seeking in Ugandan children: a case-control study. Am J Trop Med Hyg. 2017;97:1513-23.

37. Lim S, Yasuoka J, Poudel KC, Ly P, Nguon C, Jimba M. Promoting community knowledge and action for malaria control in rural Cambodia: potential contributions of Village Malaria Workers. BMC Res Notes. 2012;5:405.

38. Chitunhu S, Musenge E. Direct and indirect determinants of childhood malaria morbidity in Malawi: a survey cross-sectional analysis based on malaria indicator survey data for 2012. Malar J. 2015;14:265.

39. Do M, Babalola S, Awantang G, Toso M, Lewicky N, Tompsett A. Associations between malaria-related ideational factors and care-seeking behavior for fever among children under five in Mali, Nigeria, and Madagascar. PLOS ONE. 2018:13:e0191079.
40. Dalaba MA, Welaga P, Oduro A, Danchaka LL, Matsubara C. Cost of malaria treatment and health seeking behaviour of children under-five years in the Upper West Region of Ghana. PLoS ONE. 2018;13:e0195533.

41. Suswardany DL, Sibbritt DW, Supardi S, Chang S, Adams J. A critical review of traditional medicine and traditional healer use for malaria and among people in malaria-endemic areas: contemporary research in low to middle-income Asia-Pacific countries. Malar J. 2015;14:98.

42. Louis JP, Trebucq A, Hengy C, Djin-Djon F, Job HC, Fokoua C, et al. [Health care accessibility and adequacy of health care system in the Sanaga basin (Central Cameroon)](in French). Med Trop (Mars). 1991;51:327-33.

43. Ministry of Health Republic of Indonesia. General guidelines for alert village active. Jakarta: Health Promotion Center, Secretary General of the Indonesian Ministry of Health; 2010.

44. Amoran OE, Onwumbe OO, Salami OM, Mautin GB. The influence of environmental sanitation on prevalence of malaria in a rural town in south-western Nigeria. Niger J Med. 2014;23:254-62.

45. Morakinyo OM, Balogun FM, Fagbamigbe AF. Housing type and risk of malaria among under-five children in Nigeria: evidence from the malaria indicator survey. Malar J. 2018;17:311.

46. Tusting LS, Ippolito MM, Willey BA, Kleinschmidt I, Dorsey G, Gosling RD, et al. The evidence for improving housing to reduce malaria: a systematic review and meta-analysis. Malar J. 2015;14:209.

47. Monteiro TH, Chaves Tdo S, Matos HJ, Sofffiatti NF, Guimaraes RJ, Guimaraes $\mathrm{LH}$, et al. Basic sanitation, socioeconomic conditions, and degree of risk for the presence and maintenance of malaria in a low-transmission area in the Brazilian Amazon. Rev Soc Bras Med Trop. 2015;48:573-9.

48. Bradley J, Rehman AM, Schwabe C, Vargas D, Monti F, Ela C, et al. Reduced prevalence of malaria infection in children living in houses with window screening or closed eaves on Bioko Island, equatorial Guinea. PLoS ONE. 2013;8:e80626.

49. Liu JX, Bousema T, Zelman B, Gesase S, Hashim R, Maxwell C, et al. Is housing quality associated with malaria incidence among young children and mosquito vector numbers? Evidence from Korogwe, Tanzania. PLoS ONE. 2014;9:e87358.

50. Ernst KC, Lindblade KA, Koech D, Sumba PO, Kuwuor DO, John CC, et al. Environmental, socio-demographic and behavioural determinants of malaria risk in the western Kenyan highlands: a case-control study. Trop Med Int Health. 2009;14:1258-65.
Ready to submit your research? Choose BMC and benefit from:

- fast, convenient online submission

- thorough peer review by experienced researchers in your field

- rapid publication on acceptance

- support for research data, including large and complex data types

- gold Open Access which fosters wider collaboration and increased citations

- maximum visibility for your research: over 100M website views per year

At BMC, research is always in progress.

Learn more biomedcentral.com/submissions 